\title{
Erratum to: Randomized clinical trial of fibrin glue versus tacked fixation in laparoscopic groin hernia repair
}

\author{
Mette A. Tolver · Jacob Rosenberg • \\ Poul Juul $\cdot$ Thue Bisgaard
}

Published online: 15 June 2013

(C) Springer Science+Business Media New York 2013

\section{Erratum to: Surg Endosc}

\section{DOI 10.1007/s00464-012-2766-6}

In the Introduction section there is a misprint in the first line. "Use of a traumatic fixation devices, such as fibrin glue..." should be changed to "Use of atraumatic fixation devices, such as fibrin glue..."

In the Results section there is a misprint regarding the outcome "Incidence of foreign-body sensation" at 6 month. It says in the paper that there is no difference between groups ( 1 vs. 9 patients) $p=0.616$. However, the correct number is ( 9 vs. 12 patients).

The online version of the original article can be found under doi:10.1007/s00464-012-2766-6.

M. A. Tolver $(\bowtie) \cdot$ T. Bisgaard

Department of Surgery, Køge Hospital, University

of Copenhagen, Lykkebækvej 1, 4600 Copenhagen, Denmark

e-mail: mette.astrup@gmail.com

J. Rosenberg

Department of Surgery, Herlev Hospital, University

of Copenhagen, Herlev Ringvej 75, 2730 Copenhagen, Denmark

P. Juul

Private Hospital Aleris-Hamlet, Gyngemose Parkvej 66,

2860 Gladsaxe, Søborg, Denmark 